JD

75,6

1230

Received 17 December 2018

Revised 5 April 2019

Accepted 8 April 2019

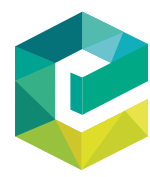

Journal of Documentation Vol. 75 No. 6,2019 pp. $1230-1257$ Emerald Publishing Limited $0022-0418$ DOI 10.1108/JD-12-2018-0210

\section{Adopting situationally relevant modes of music information at different stages of information-seeking processes A longitudinal investigation among music students}

\author{
Antti Mikael Rousi, Reijo Savolainen and Pertti Vakkari \\ Faculty of Information Technology and Communication Sciences, \\ University of Tampere, Tampere, Finland
}

\begin{abstract}
Purpose - The purpose of this paper is to elaborate the picture of situational relevance by examining how modes of music information are viewed as situationally relevant at different stages of information-seeking processes among music students.

Design/methodology/approach - Empirical data of the present longitudinal study were collected in two phases by utilizing questionnaire and interview methods. Informants comprised of 14 university-level music students representing the fields of music performance, music education and music theory and composition. Modes of music information were approached through the information typology presented by Rousi, Savolainen and Vakkari. Findings - The findings indicate that not only the modes of music information were seen as situationally relevant for different reasons by the three participating music student groups when at the beginning of their tasks, but also that the perceived situational relevance of the information modes underwent changes as their tasks progressed to focus formulation and post-focus stages.

Research limitations/implications - Due to the small number of participants, further research is needed to verify the results concerning the differences in information-seeking processes between diverse music student groups.

Originality/value - The paper showcases that approaching music information through frameworks that classify information sources at diverse levels of abstraction enables an accurate description of information-seeking processes and illuminates context-sensitive development of situational relevance of music information of diverse modes.
\end{abstract}

Keywords Music, Relevance, Music information, Information seeking, Information search process,

Music students

Paper type Research paper

\section{Introduction}

Kuhlthau's (2004, p. 112) information search process (ISP) model suggests that information types at varying levels of abstraction may have differentiated interpretations during information-seeking process, and that these interpretations can undergo change as such processes progress. Music is a domain where information resides not merely in written language. In their works on musicology and musical semiotics, Bengtsson (1977) and Tarasti (1994, p. 4) state that musical knowing transpires through sign systems such as

(C) Antti Mikael Rousi, Reijo Savolainen and Pertti Vakkari. Published by Emerald Publishing Limited. This article is published under the Creative Commons Attribution (CC BY 4.0) licence. Anyone may reproduce, distribute, translate and create derivative works of this article (for both commercial \& non-commercial purposes), subject to full attribution to the original publication and authors. The full terms of this licence may be seen at http://creativecommons.org/licences/by/4.0/legalcode

The authors would like to thank the anonymous reviewers for their constructive comments that greatly helped us to improve the manuscript. 
music notations, aural experiences and gestural language of music making. This suggests that the interpretation and relevance of music information of varying kinds may change during an information-seeking process. When juxtaposing the dynamic nature of relevance suggested in the ISP model with the above multifaceted notion of music information of musicology and musical semiotics, an anomaly becomes apparent. Prior studies have left open the following question: which modes of music information are viewed as situationally relevant during the different stages of information-seeking processes?

In general, studies on situational relevance examine the relationships between information and the user's information problem situation (Schamber, 1994, p. 8; Saracevic, 2007, p. 1930). The present paper approaches the relevance of music information in relation to situational requirements of accomplishing a study-related information-seeking task on music. Prior to the present paper, the issue of music information objects and relevance have predominantly been discussed within the field of music information retrieval (MIR) (e.g. Casey et al., 2008; Kim, 2015). Even though there are situational factors, such as user's location (e.g. Cheng and Shen, 2014) and time of day (e.g. Su et al., 2010), included in MIR's approach to relevance, we lack investigations examining how music students view the situational relevance of music information of varying kinds during the different stages of performing their information-seeking tasks. Neither studies describing and modeling information seeking and needs of musicians (e.g. Brown, 2002; Kostagiolas et al., 2015; Lavranos et al., 2015, 2016) have devoted due attention to the particular nature of the modes of music information and their situational relevance. Even though there are a few studies of information seeking examining the situational relevance of music information (see Rousi et al., 2018), none of these prior studies focus on how the situational relevance of music information of diverse modes is viewed during the different stages of information-seeking tasks.

To fill gaps in empirical research on context-sensitive information-seeking processes, the present paper examines how music students representing different fields and levels of university studies adopt situationally relevant modes of music information during the different stages of performing their information-seeking tasks. The term music information mode refers to a set of information sources that are seen to represent music information at a certain level of abstraction. In other words, the concept of music information mode is used to group information sources based on their method of representation, be it gestural language, non-conceptual aural experiences of music or symbolic written representations, for example. To conceptualize these modes, the present paper utilizes the typology of music information proposed by Rousi et al. (2016). Six modes were identified: music making as the first mode of enactive representations; music listening as the second mode of enactive representations; iconic representations of music; technological models of music as the first mode of symbolic representations; and ideological models of music as the second mode of symbolic representations and other symbolic information.

The present paper utilizes a longitudinal research design where the situational relevance of the modes of music information are qualitatively analyzed at two phases during the information-seeking tasks performed by the music students. Furthermore, the progress of the participants' information-seeking task processes was examined from the viewpoint of thoughts, actions and emotions by using a modified process survey instrument of the ISP model (see Kuhlthau, 2004, p. 60). The empirical material was collected in 2013-2015 by using survey and interviews methods. The participants comprised of 14 music students representing music performance, music education and music theory and composition. All the participants were Finnish music students of Sibelius Academy, Helsinki University of the Arts.

The rest of the paper is structured as follows. First, to provide a background, the literature review introduces the typology of the modes of music information used in the present study; this section also describes diverse approaches to situational relevance and 
$\mathrm{JD}$

75,6

characterizes the main features of studies of relevance of music information objects and Kuhlthau's ISP model. Then, the research questions and the empirical research design are specified. The main part of the paper focuses on the report of the empirical findings. The concluding section discusses the findings and reflects their significance.

\section{Literature review}

Modes of music information

The typology of music information used in the present study was created by integrating Tarasti's (1994) music semiotic ideas with Bruner's (1966) approach to modes of knowledge representations introduced in Bruner's book, Toward a Theory of Instruction. According to Bruner, any domain of knowledge and every single problem within that domain can be presented to the learner through using the following modes of representation: Enactive mode of representation refers to sequences of activities for creating desired results. Iconic mode of representation refers to presenting a concept through a graph without exhaustively defining it. Most abstract of the modes is the symbolic mode where through a system that defines rules of expression, a set of arguments is created for describing a concept (Bruner, 1966, pp. 44-45). The proposed typology further defined the content of Bruner's modes within the domain of music by positioning sign systems relevant to music presented by Tarasti (1994) in Theory of Musical Semiotics into them, which led into altogether six following modes of information (Rousi et al., 2016):

(1) Music making as the first mode of enactive representations refers to information resided in different sequences of actions that produce sounds for musical purposes. This action may appear in varied forms, such as playing the violin, singing or creating electronic music with a computer.

(2) Receiving music as the second mode of enactive representations refers to receiving musical performances, while being present at a performance or through a recording, without the control over the performance's sonic results. Audio recordings played using either home audio devices or mobile online music streaming services function as examples of sources incorporating this second mode of music information.

(3) Iconic representations of music refer to the graphic illustrations presenting musicrelated information. Different notations, such as modern staff notations, function as an example of sources incorporating this mode of music information.

(4) Technological models of music as the first mode of symbolic representations refer to examining structures of music, i.e. tonal organization of harmony and counterpoint and sonic formulae of orchestration and interpretation, for example, through symbolic means such as written language. Information sources that incorporate the first mode of symbolic representations are, for example, textbooks of harmony and counterpoint.

(5) Ideological models of music as the second mode of symbolic representations address music at a symbolic level but not directly the qualities that transpire in audible music. In this mode, conceptual symbolism regarding music are negotiated with other fields and their conceptual symbolic representations. For example, it is possible to produce narratives on concepts such as "Western classical music" and "history" or "music" and "aesthetics" without reference to actual phenomena present in sonic reality of music. Examples of information sources that can be more geared towards the second symbolic mode include monographs on philosophy of music and some texts concerning the history of music, such as some biographies of composers. 
(6) As music students might also have other than music-related information needs, such as information needs about academic writing, a sixth information category titled other symbolic information was added into examination. This category was defined to include all symbolic, i.e. conceptual, information sources from other than musicrelated disciplines, such as conventions of scientific writing.

The typology's purpose is not to exhaustively classify phenomena as belonging to one mode alone. The position and needs of the information seeker play a crucial role in providing the angle through which the different modes of music information transpire. For example, the technological models of harmony and counterpoint are closely weaved with the history of Western music, which is evident in concepts such as "Palestrina style counterpoint" (see also Tarasti, 1994, p. 17). Thus, the same information sources can very well include many of the modes of music information.

\section{Situational relevance}

Whereas systems or algorithms create relevance by retrieving documents based on the query, people derive relevance from obtained information objects (Saracevic, 2007, p. 1919). Situational relevance refers to examining relationships between information and the user's information problem situation (Schamber, 1994, p. 8; Saracevic, 2007, p. 1930). Relevance inferences depend not only on the features of the information in document, but also on user's context, user's previous knowledge and specific qualities sought (Barry, 1998, p. 1302). The situational relevance approach differs from topical relevance approach where the focus is on the relationship between the topic expressed in a search query and topic covered by resulting information objects (Saracevic, 2007, p. 1929; 1931). Concepts such as success dimensions, criteria categories and factors influencing selection of information objects, e.g. documents, have been used to describe the outcomes of previous research examining situational relevance (Schamber, 1994, pp. 24-25). In the present paper, however, the construct of situational relevance type was preferred. This is due to the fact that such types are approached as situational factors that make the seeking of diverse modes of music information pertinent to the performance of ongoing study tasks among students working on their theses and dissertations.

\section{Music information objects and relevance}

The issue of music information objects and relevance has predominantly been discussed within the field of MIR. MIR studies have examined relevance of music information objects through context-based approaches matching string search queries with textual metadata representations and through content-based approaches matching music similarity of audio data examining rhythm and melodies (e.g. Downie, 2003; Downie, 2004; Casey et al., 2008; Kim, 2015). In MIR, the approaches to relevance are often more system than user oriented. MIR's conceptualization of music information provide useful summaries for MIR system design (e.g. Downie, 2003, pp. 293-301) but may not be sufficient from the viewpoint of a person engaged in music information seeking to whom gestural language of music making (Godøy and Jensenius, 2009) and diverse literature (Brown, 2002, p. 82) may also be relevant. Currently, there are also users' situational or contextual factors incorporated into MIR techniques. For example, context-aware music recommender systems utilize the following contextual data when suggesting content. User's mood or emotion (Kim et al., 2010); daily activities, such as working, sleeping and running (Wang et al., 2012); user's location (Cheng and Shen, 2014); and time of day (Su et al., 2010). However, these factors are general in their nature, and do not tell why, for example, music students see the different modes of music information situationally relevant in different stages of their information-seeking tasks. 
JD

75,6

1234

Studies describing and modeling information seeking and needs of musicians and music scholars confirm that both groups have information needs spanning to diverse information sources representing music information at varying levels of abstraction (Brown, 2002; Hunter, 2006; Liew and Siong, 2006; Lai and Chan, 2010; Matson and Shelley, 2013; Dougan, 2015; Kostagiolas et al., 2015; Lavranos et al., 2015, 2016). For example, music performances, recordings, notations and music-related literature are identified as information need types, albeit amongst many, by previous studies (e.g. Kostagiolas et al., 2015, p. 7). Brown's (2002, p. 82; 86) findings suggest that music scholars utilize, for example, audio recordings and music notations while conducting research. In general, the above studies have not devoted due attention to the particular nature of the modes of music information and the ways in which music students evaluate their situational relevance. Currently, there are some studies of music-related information seeking and information behavior that have approached music information's situational relevance through the many layers of music information (Rousi et al., 2018; see also Pohjannoro and Rousi, 2018). However, prior to the present paper, there are no longitudinal studies examining which modes of music information are viewed as situationally relevant during the different stages of information-seeking processes?

\section{ISP model}

As stated in the introduction, Kuhlthau's (2004) ISP model enables the process approach by providing a framework for the analysis of the information-seeking tasks of the music students. In a series of empirical studies, Kuhlthau (2004) demonstrated that information-seeking tasks consist of several stages. The ISP model proposes that information-seeking tasks typically consist of six consecutive stages: initiation, selection, exploration, formulation, collection and presentation (Kuhlthau, 2004, p. 44-50). These stages are significant as person's thoughts, actions and emotions typically undergo change as one's information-seeking task progresses from stage to another. According to the model, the formulation is a pivotal stage during which a more focused perspective to the task is gathered. After focus formulation, person's sense of direction and confidence increases and actions change from exploring relevant information to seeking and documenting pertinent information (Kuhlthau, 2004). The ISP model has gained a prominent role among theories of information seeking and has affected theory building in Information science (Vakkari, 2001). It has previously provided a process framework for studies examining the changing relevance criteria of textual documents during information-seeking tasks (Bateman, 1998; Vakkari and Hakala, 2000). Even though music-related information seeking has been described and modeled in previous studies (Lavranos et al., 2016), which situationally relevant modes of music information are adopted by music students during different stages of their information-seeking tasks has not been previously examined through the ISP model or any other process-oriented framework of information seeking.

\section{Methods}

\section{Research question}

The goal of the present paper is to elaborate the picture of situational relevance by examining how modes of music information are viewed as situationally relevant at different stages of information-seeking processes among music students representing different fields of university studies. To this end, the present paper addresses the following research question:

$R Q 1$. Which situationally relevant modes of music information are adopted during the information-seeking processes of music students representing the fields of music performance, music education and music theory and composition? 
Participants. All of the 14 participants of the present study were students in Sibelius Academy, Helsinki University of Arts in Finland. The participants of the present paper represented three different music student groups of Sibelius Academy. Six of the participants were Doctor of Music (DocMus) students focusing on music performance. Their dissertation projects included both a series of five concerts and a written part. During the present study, the participating DocMus students had written and submitted their final dissertation proposal for examination. In their proposals, both the concert programs and the topic of the written dissertation were defined. Five of the participants were students of music performance specializing in music education. Their theses were written and no music performances were included in their grading. One of the students who focused on music education was a DocMus student, i.e. PhD level student, and four were working on their Master's theses. Lastly, three of the participants were students of music theory and composition who were also working on their Master's theses. Also, the theses of the students of music theory and composition were written and focused on music analyses; no music performances were included in their grading. Before the first data collection phase of the longitudinal study, both groups of Master-level students had begun their Master's thesis.

These three main student groups were selected as the participants of the present study due to that they were seen to represent three different task types common to music students: preparing music performances, writing academic texts on music education and conducting music theoretical analyses. By including these three participant groups, the present study seeks to elaborate the picture on how music students representing different fields view the situational relevance of music information modes during the different stages of performing their information-seeking tasks.

The participating DocMus students were recruited from an information retrieval course arranged for the DocMus students by Sibelius Academy, Helsinki University of Arts Library. The participating Master-level students of music education and music theory and composition were recruited from their respective Master's thesis seminars. All 14 music students were awarded a sum of $€ 40$ for their participation in the longitudinal study of the present paper.

Even though the amount of participants per student group is small, they represent a fairly large sample of all students annually participating in both the DocMus programs and the respective Master-level seminars. Within the period of 2010-2018, on average, six Doctors of Music focusing on music performance have graduated per year from the Sibelius Academy, Helsinki University of Arts. As the recruitment of DocMus students $(n=6)$ spanned from the semesters of 2013-2014 and 2014-2015, it may be estimated that the three participants per semester constitute a significant proportion of all students starting in the respective program on the given year. The DocMus student focusing on music education $(n=1)$ was from the researcher program of the doctoral school of Sibelius Academy, Helsinki University of Arts. Respectively, on average, four Doctors of Music have graduated within the period of 2010-2018 from the researcher program. The Master's level students of music education $(n=4)$ were recruited from two Master's level seminars in which there were circa ten active participants in total. The students of music theory and composition $(n=3)$ were recruited from a Master's thesis seminar with circa five active participants. With both Master's level students focusing on music education and music theory and composition, the data collection was limited to the semester of 2013-2014. This was due to that several students continued in the seminar also in the following semester, which enabled the recruiting of new participants by continuing data collection in semester 2014-2015. 
JD

75,6

\section{Data collection methods}

The data collection methods of the present study included survey questionnaire and interview methods. To examine how the music students progressed in their informationseeking tasks, the present investigation utilized survey questionnaires. In the initial section of the questionnaire, the participants were asked to assess whether they thought their tasks had progressed. During both data collection phases, the participants chose the current stage of their information-seeking task from the three stages identified by Vakkari (2001, p. 47): start of the thesis and identifying its general topic (pre-focus); examining information concerning a general topic and formulating a specific focus (focus formulation); and gathering information pertinent to a focused topic or finalizing the thesis (post-focus). Whereas the rest of the questionnaire used in the present study drew on the process survey instrument developed by Kuhlthau (2004, p. 60), Vakkari's (2001, p. 47) operationalization of the stages of information-seeking tasks was made at a higher level of generality so that it would suit to the examination of tasks incorporating music performances.

To further support the participants' self-assessment of the progress of task performance, as well as the changes in thoughts, actions and emotions, the process survey instrument developed by Kuhlthau (2004, p. 60) was modified for the purposes of the present study as follows. The questions examining the information seeker's current emotions and thoughts were translated into Finnish and used as such in the data collection. The section examining current activities was also modified to include music-related activities. Music listening, performing music and conducting music analyses were added as options among the original actions listed in Kuhlthau's (2004, p. 60) process survey instrument. To include the process aspect in the music-related activities, two options of each of these activities of playing music, listening to music and conducting music analyses were given in the questionnaire. One of the options reflected a more focused approach to the activity, such as "I conduct detailed music analyses related to my topic" while another option exemplified a less focused approach, such as "I conduct preliminary music analyses related to my topic." Both the thoughts, actions and emotions in the original process survey instrument (Kuhlthau, 2004, p. 60), and the added music-related activities were listed in the questionnaire. The participants were asked to choose all that apply during both data collection stages. The questionnaire used is included as Appendix 1 (translated from Finnish to English by the first author).

The third main part of the questionnaire focused on the situational relevance of the six information modes presented in the literature review (Rousi et al., 2016). Each information mode had its own section in the questionnaire. Within these sections, the participants were first asked to indicate on a four-point scale (not at all important, not that important, important and very important) how pertinent each of the modes was for their tasks of either a dissertation or a Master's thesis in music and then to briefly write down the reasons behind these assessments. The information mode-specific sections of the questionnaire also included definitions of the information modes and examples of information sources of individual modes were provided (see Appendix 1).

The use of questionnaires was complemented with interview methods. A thematic interview guide was developed to ask more detailed questions regarding the participants' thesis tasks and to allow the participants to elaborate answers given in the questionnaires. Overall, the interview guide consisted of two main sections: general questions regarding the topic and progress of the participants' thesis tasks and sections examining the situational relevance of the six information modes. Within the music information mode-specific sections, the participants were able to explain in depth why a specific information mode was or was not important for their information-seeking tasks and whether they saw that its situational relevance had changed during the information-seeking process. The interview data consist of circa $630 \mathrm{~min}$ of audio-taped records. 
The empirical data were collected in two phases. First, during autumn semesters of 2013 or 2014, the 14 participants were asked to fill in the survey consisting of the sections described previously. All of the 14 students also participated in the latter phase of data collection, which took place during the following year's spring semester. During the latter phase, the participants were first asked fill in again the same set of survey questions regarding their thoughts, actions and feelings after which their answers were further elaborated in an interview. Second, the participants were asked to the fill in the sections concerning the importance individual modes of music information as in the previous phase; each of these were complemented with interview questions. Once the individual music information mode sections were covered during the second phase of data collection, the previous answers given in the first phase survey were shown to the participants; thereafter, any differences identified in mode-specific situational relevance assessments were discussed. The average time period between the first and second data collection phases was circa 135 days. The shortest period was circa 100 days and longest circa 160 days. Table I summarizes the data collection process.

\section{Research ethics}

The informed consent form was given for the scrutiny of the participants at both data collection stages. The form offers information about the voluntary nature of the study, the participants to right withdraw from the study at any given stage and the anonymized reporting of the results and data. Agreeing to participate in the interviews was interpreted as the informant's consent to participate in the study. If a participant returned the questionnaire during phase 1 , but did not participate in the second phase of data collection, their data were discarded and thus not used in the present study. Direct identifiers were collected only as part of the interview data, i.e. the voice of the participant. However, given that the overall music student population is small, the indirect identifiers included in the data become increasingly efficient in identifying the participants. Therefore, the questionnaire data, interview audio recordings and the transcript data will be deleted after they are no longer used for scientific purposes. The participants' anonymity is also protected when reporting quotes from the transcribed data in the findings section. Italicized notes are used to replace a specific section of the quote with a more general expression in cases in which the specific part contained an indirect identifier that would compromise the anonymity of the participant.

\begin{tabular}{|c|c|}
\hline $\begin{array}{l}\text { Data collection phase } 1 \\
\text { Questionnaire } 1\end{array}$ & $\begin{array}{l}\text { Data collection phase } 2 \\
\text { Questionnaire } 2\end{array}$ \\
\hline \multicolumn{2}{|l|}{ Progress in the task performance } \\
\hline $\begin{array}{l}\text { Participants' self-assessments } \\
\text { regarding the progress of their } \\
\text { information-seeking tasks }\end{array}$ & $\begin{array}{l}\text { Participants' self-assessments } \\
\text { regarding the progress of their } \\
\text { information-seeking tasks }\end{array}$ \\
\hline $\begin{array}{l}\text { Current thoughts, actions } \\
\text { and feelings }\end{array}$ & $\begin{array}{l}\text { Current thoughts, actions } \\
\text { and feelings }\end{array}$ \\
\hline
\end{tabular}

Situational relevance of the six information modes Situational relevance of the information modes

The perceived importance of

the mode

Description of why the mode was considered as important or not important

\section{Music information}

1237
Interview guide

Questions regarding the task of the participants, e.g.

What is the topic of your thesis?

Do you have a focus in your task?

What are you planning to do next? What kind of information are you looking for right now?

Questions regarding the changing situational relevance of the information modes

Has the reason why the mode is important changed? Comparison of mode-specific answers of questionnaires 1 and 2
Table I.

Summary of data collection process 
JD

75,6

1238

Data analysis and validity issues

To examine the progress occurring in the tasks of the participating music students, their self-assessments regarding the progress of their information-seeking tasks were first summarized. To achieve this, it was examined how the participants were distributed regarding the self-reported stages of the task performance process per phase of data collection. Second, the participants' answers to the modified process survey questionnaire were summarized so that the percentual distributions of participants expressing different thoughts, actions and emotions were examined per phase of data collection. Due to the small number of the participants, no correlations or statistical tests will be conducted. However, descriptive statistics are calculated with regard to the stage of the participants' tasks and thoughts, actions and emotions at both data collection phases to support the qualitative analysis that result in student group summaries. The findings regarding these are presented using descriptive statistics so that they highlight the changes occurred in the participants' thoughts, actions and emotions during the longitudinal study.

With the questionnaire and interview data examining the perceived importance of the music information modes and their situational relevance, the analysis was conducted as follows. First, the questionnaire data were summarized by calculating information modespecific averages of perceived importance. Second, the interview data were transcribed and scrutinized through qualitative content analysis. More specifically, the open-ended answers explaining the perceived importance assessment of an information mode were interpreted to indicate its types of situational relevance. To this end, an attempt was made to identify reasons by which the participants considered a music information mode important to task performance; such reasons were used as a point of departure to identify the situational relevance types reviewed in the findings section below. To detect the changes occurring in the situational relevance types, the constant comparative method (Tesch, 1990, p. 96; Silverman, 2005) was used to discern conceptual similarities between the open-ended answers obtained during both data collection phases. If a conceptual dissimilarity was observed in the open-ended answers, the full interview data were further scrutinized for more evidence of changing situational relevance of an information mode.

Even though the empirical data are already six years old, it was seen as valid for the particular needs of the present investigation. It examines which situationally relevant modes of music information are adopted during preparing a thesis focusing music performance, music education and music theoretical analyses. Analysis is not conducted on the level of individual information sources per se, but on the more general level of music information modes, each categorizing music information at a different level of abstraction. As the processes of giving concerts in the Western art music tradition, writing academic texts on music education and conducting music theoretical analyses are grounded in their cultural traditions (see e.g. Kuhn, 1996; Trehub et al., 2015), their core information elements do not change so rapidly than the quickly developing field of online music information sources and music streaming services, for example.

To improve the validity of this study, the following section incorporates quotes taken from the interview data. The quotes were translated from Finnish into English by the first author. Care was put into preserving the quotes as close as possible to verbatim form during the translation process.

\section{Findings}

The findings section is organized as follows. First, the summary of participants' self-assessments regarding the progress of their information-seeking tasks is presented. Second, descriptive statistics regarding the changes of the participants' thoughts, actions and emotions between data collection phases are presented to demonstrate whether they - in line with Kuhlthau's (2004) ISP model - indicated progress in the task performance. 
Third, the perceived importance and situational relevance of the music information modes are reviewed. The situational relevance of modes of music information is qualitatively described with illustrative extracts taken from the empirical data. Lastly, the results are summarized per music student group to provide an overview on how situationally relevant modes of music information are adopted at the different stages of information-seeking processes among music students representing the fields of music performance, music education and music theory and composition.

Participants' self-assessments regarding the progress of their information-seeking tasks

The participants' self-assessments revealed that circa half of the participants thought that they had moved to a new stage in their information-seeking at the time of the second phase of data collection. Five participants indicated that they had moved from the focus formulation stage to post-focus stage at the second phase of data collection. Respectively, two of the participants indicated that they had moved from pre-focus stage to focus formulation at the second phase of data collection. Table II specifies how the participants were distributed into various stages of the task performance, based on their selfassessments during the data collection phases I and II.

\section{Thoughts, actions and emotions of the participants}

The participants' answers to the thoughts, actions and emotions sections of the modified process survey questionnaire are presented next. The answers were summarized so that the percentage distributions of participants expressing different thoughts, actions and emotions were examined per phase of data collection highlighting the changes occurring between data collection phases. The purpose of the descriptive statistics is to support the qualitative analysis resulting in the student group summaries presented later in this findings section.

The changes in thoughts reported by the participants in both phases of data collection suggest that their information-seeking tasks had progressed. In total, 57 percent of the participants reported they were "recognizing ways to draw the project to close" during the second phase, whereas only 28 percent reported this at the initial phase. Also, the share of participants "seeking information about my specific area of concentration" rose to 64 percent at the time of the second phase from the 43 percent participants reporting this in the first phase. The share of participants who reported to be "identifying possible alternative topics" dropped from 57 percent in the first phase to 29 percent in the second phase. Also, the share of participants reporting they were "becoming informed about the general topic" dropped from 71 to 43 percent during the second phase of data collection. The entire results concerning changes in the category of thoughts are presented in Table AI.

The changes in the participants' actions support the above findings in that their tasks had progressed during the data collection process. The amount of participants reading literature rose from 71 to 86 percent at the second phase of data collection. Writing about themes and ideas rose from 36 to 50 percent and the share of participants trying out music pieces with their instrument rose from 29 to 43 percent. Actions with decreasing shares

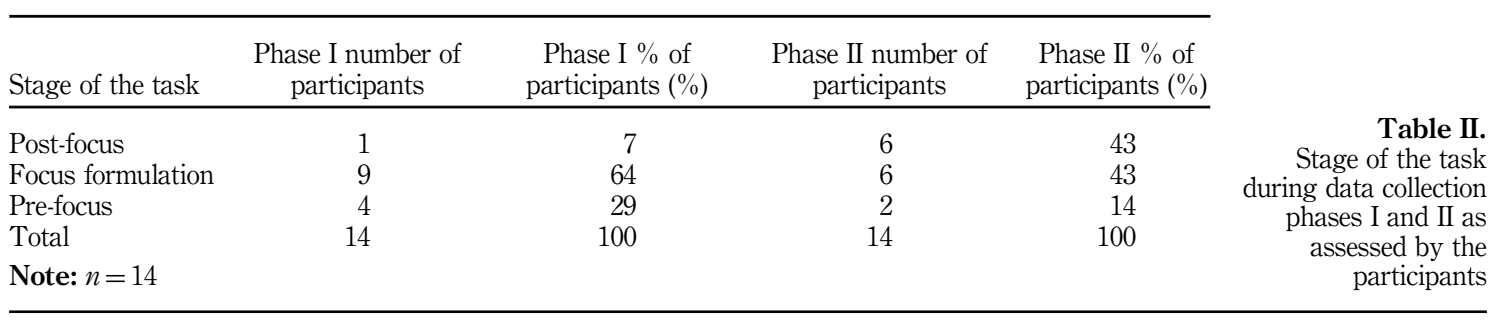


JD

75,6

1240 included "making a preliminary search from the library" (from 64 to 21 percent), "conferring with people who know the topic" (from 50 to 11 percent) and "reading over notes for themes (from 43 to 7 percent). The entire results concerning changes in the category of actions are presented in Table AII.

Similar to thoughts and actions, changes in emotions suggest that the participants' tasks had progressed when the changes are examined through Kuhlthau's (2004) ISP framework. Amongst the participants, positive feelings had increased during the second phase of data collection. For example, the share of participants feeling optimistic increased from 66 to 86 percent. Furthermore, 21 percent of the participants reported feeling relieved during the second phase whereas none did so during the initial phase. Respectively, the share of participants reporting negative emotions decreased during the data collection. In sum, 50 percent of the participants reported feeling confused at the first phase and none did so during the second. Furthermore, 36 percent of the participants reported feeling doubtful during the first phase and 14 percent did so during the second. The entire results concerning in the category of emotions are presented in Table AIII.

The changes in thoughts, actions and emotions of the participants suggest that their tasks had progressed during the circa 130 days between the two data collection. Even though the data of the present study do not evidence that the tasks of all of the 14 participants had progressed, the analysis revealed that the tasks of circa half of the participant underwent significant progress between the data collection points. Furthermore, when examined at the level of individual participants, hints of progress were present in the changes of thoughts and actions of altogether four participants who did not report progress in their assessments.

\section{Perceived importance of modes of music information}

The scrutiny of the participants' questionnaire answers revealed that the perceived importance of the modes of music information did not undergo major changes between the phases of data collection. However, the information modes seen as important varied between the student groups participating in the present study. DocMus students focusing on music performance saw diverse information modes relevant for their tasks and viewed iconic mode, music making as the first mode of enactive representations and receiving music as the second mode of enactive representations as the most important (see also Rousi et al., 2018). The tasks of the students of music theory and composition were primarily music theoretical analyses of a musical piece or pieces; these students viewed the same information modes as important similar to DocMus students. However, in contrast to DocMus students, the students of music theory and composition saw technological models of music as the first mode of symbolic representations as important. Compared to the above student groups, the students focusing on music education viewed somewhat different information modes as important. Their focus appeared to be to strive to narrow their focus into the most relevant symbolic information mode, which, within the data of the present paper, was ideological models of music as the second mode symbolic representations. See Table AIV for the average perceived importance of modes of music information categorized per music student group.

\section{Situational relevance types of the modes of music information}

The open-ended answers explaining the assessment of perceived importance of an information mode were indicative of the types of situational relevance. Furthermore, the qualitative analysis discerning conceptual dissimilarities between the answers specific to a data-collection phase were used to identify how the mode's situational relevance changed as the tasks of the participants progressed. What follows is a section in which the changes in the situational relevance of the modes are examined in more detail per music information mode. 
Among DocMus students, music making as the first mode of enactive representations was seen important in the early phases of their dissertation tasks primarily for the reason of gaining mastery of the gestural language of the concert pieces. One of the DocMus students reported a change in the situational relevance in conjunction with focus formulation: after focus formulation, he had interest in both personal rehearsal of gestural language of the concert pieces, but also in how players of a certain instrument used their arm in certain musical passages. The present study's findings suggest that gestural language of music making is also relevant for music students working on written theses of music analysis and music education. A student of music theory and composition explained how she used own playing to study the details of the analyzed piece and how the importance of this function of her own playing increased after getting initially acquainted with the piece through listening recordings of the piece. A student focusing on music education explained that as the topic of his thesis grew more focused, he realized how much his own approach to his instrument affected his approach to his task:

Music education student A: "My topic has to do with music education so it is important maintain one's ability with one's instrument." (1st phase, survey)

Music education student A: "Well, one can approach singing in so many ways and yet [...] Yet get the results. [...] So in a way it [thesis] mirrors my own subjective view of singing which again is based on, as I still study, my teacher's approach. [...] So in that sense, my own approach has a great impact on this. Also in a way that through my own approach I contemplate that what are results of this. [...] Well, now I have observed that [...] in that previous phase I had a more detached approach and were thinking that I just sing and of course I have to know how to sing to be able to do what I am doing." (2nd phase, interview)

\section{II: receiving music as the second mode of enactive representations}

Among DocMus students focusing on music performance, the change dynamics within the situational relevance of receiving music as the second mode of enactive representations appeared differently during the task performance process. In the starting phases of the task, listening to audio recordings or using music streaming services was important for the sake of getting acquainted with large amounts of musical material which helped to narrow down the focus of the theses. After focus formulation, listening to audio recordings could gain entirely new situational relevance types and it was used for detailed study and analyses of the pieces chosen to be included, for example. Also, the students of music theory and composition listened to audio recordings and used online music streaming services to get acquainted with the pieces in focus of the analyses. With students of music theory and composition, it was possible that the importance of this music information mode diminished in the later phases of the task, as the students were focusing on finalizing the music theoretical analyses of the pieces. Furthermore, regardless of the music student group, if the focus of the task was redefined between the phases of the data collection, this mode of music information could become of relevance due to new focus in task. The following extracts illustrate how the situational relevance of receiving music as the second mode of enactive representations changed for students of music theory and composition after focus formulation:

Student of music theory and composition B: "It [ $2^{\text {nd }}$ enactive mode] is especially important, if the piece exceeds your own capabilities as [a player of a certain instrument], which in turn leaves the audible picture of the piece vague." (1st phase, survey)

Student of music theory and composition B: "Well, it changes so that once you have gotten acquainted with a piece, you listen to it considerably less." (2nd phase, interview) 
JD

75,6

1242

\section{III: iconic representations of music}

With iconic representations of music, the most prominent changes in situational relevance was again found from the data of DocMus students focusing on music performance. Within the early phases of the task performance, music notations were used to gain familiarity with the gestural language of the concert pieces. However, within later phases of the task, the situational relevance types of music notations could be expanded to the examination of certain traditions of performance based on the interpretational cues included in the notations. Alike DocMus students, students of music theory and composition also viewed music notations as important for their tasks. However, the data of the present paper did not suggest significant changes in the mode's situational relevance during their tasks. Also, as with receiving music as the second mode of enactive representations, if the participant had redefined the focus of his or her task, the situational relevance of iconic representations of music could change abruptly due to it:

Doctor of Music student D: "It has now occurred to me that it is worthwhile to study editions from the nineteenth century [...] It appears they reflect on the traditions of performance of the era [...] So that then means this is very important." Interviewer: "Do you feel like this has gotten more important because of this finding?" Doctor of Music student D: "Yes, it has changed! This observation is less than six months old [...] As if I have found a whole new territory within last six months." (2nd phase, interview)

\section{$I V$ : technological models of music as the first mode of symbolic representations}

With the information mode of technological models of music, the following change dynamics were identified. Among DocMus students, the participants usually saw this information mode as not important before focus formulation. However, after gaining a more focused approach to their topic, several DocMus students found this mode of new relevance. The analysis of the chosen concert pieces could require the DocMus students to gain further understanding and knowledge of analysis method they were previously unfamiliar with, for example. With music education students, the relevance of technological models could diminish, as with other symbolic information, as the participants focused their topics on matters related to ideological models of music:

Doctor of Music student B: "My approach is not theoretical." (1st phase, survey)

Doctor of Music student B: "Yeah, I think this is really important. I have still study this and I cannot start studying before September. [...] Some were analysed with serialist methods and then there is the twelve-tone row and its use. I have no clue how these are done yet." (2nd phase, interview)

\section{$V:$ ideological models of music as the second mode of symbolic representations}

Music performance students focusing on music education viewed the symbolic modes as important for their tasks and focused their theses' subject matter on this information mode of ideological models of music as the second mode of symbolic representations. DocMus students focusing on music performance utilized this mode of information to provide both ideological and historical frameworks for their concert series and found this information mode useful in getting acquainted with the scientific terminology of their field (see Rousi et al., 2018). None of the DocMus students reported changes in these situational relevance types regarding this information mode. In general, the students of music theory and composition did not find this information mode as important for their tasks. Overall, no changes in situational relevance were identified from the participants' answers regarding the importance of ideological models as the second mode of symbolic representations:

Music education student C: "Well, I will now say that this is really important because in a way that when [players of a certain instrument] feel like they are closest to the music is a very abstract thing which has been defined in many different ways. So then I have taken ideas from some music philosophical and 
other philosophical texts regarding what kind of an experience this is and how it could be defined. [...] Interviewer: "Would you say that there has been any significant changes regarding this?" Music education student C:"I do not think so as I had a clear idea of this from the beginning. I feel like it has gotten more focused and such, but I do not think there has been much change."

\section{VI: other symbolic information}

The change dynamics within the situational relevance of non-music-related symbolic information varied among the participants. With DocMus students, it is both possible that new types of situational relevance emerge to non-music-related symbolic information during and after focus formulation. Respectively, especially with the participant group of music performance students focusing on music education, focus formulation could also render once important situational relevance types of other symbolic information irrelevant. As stated previously, the students focusing on music education strived in focus formulation to narrow their examination into the most relevant symbolic mode of information, i.e. ideological models of music. As a result, the situational relevance of other symbolic information modes could diminish after focus formulation occurring within this music student group. Likewise to ideological models as the second mode of symbolic representations, the students of music theory and composition did not find this information mode as important for their tasks either:

Music education student A: "I guess I have organized my thoughts regarding this so that maybe in that phase I thought that it would be more pedagogical in a certain way $[\ldots][\ldots]$ But now it is more clear. It has went to this direction that in the end it has a pedagogical dimension, but it is not really pedagogical [...] So that there would be the teaching and its contemplation, but more of contemplation of the physiology of the voice." (2nd phase, interview)

\section{Student group summaries}

This sections present summaries of the findings regarding individual participant groups. Summary tables specify important information modes and the identified changes in the situational relevance of the modes examined from the viewpoint of the three stages of the task performance (pre-focus, focus formulation and post-focus).

\section{DocMus students focusing on music performance}

The ISP of DocMus students can be described as follows. Within the pre-focus stage, the enactive and iconic modes were most important and were used to explore the topic before proceeding into focus formulation. During and after focus formulation, the importance of the symbolic modes raised for the DocMus students. On the other hand, the importance of the enactive and iconic modes remained constant during the ISPs among these students. See Table III for the summary of findings regarding this participant group.

\section{Music performance students focusing on music education}

The ISP of the music performance students focusing on music education could be characterized as focused on the symbolic information modes. During and after the focus formulation, this participant group narrowed its focus to the symbolic or textual mode which was viewed as most relevant, i.e. ideological models of music. See Table IV for the summary of findings regarding students focusing on music performance.

\section{Students of music theory and composition}

Finally, the ISP of the students of music theory and composition can be described as follows. The enactive and iconic modes were of importance for this participant group even though the output of their task was a written thesis focusing on music analyses. As with DocMus 


\section{Table III.}

Important information modes and changes in situational relevance among Doctor of Music students focusing on music performance
Changes in situational relevance

Pre-focus

Notations as the foundation of gestural language of the concert pieces (iconic mode)

Own rehearsing as the means to gain control over the gestural language of the pieces (1st enactive)

Study of the topic and concert pieces through listening of audio recordings (2nd enactive)

Pre-focus, the symbolic modes appear as secondary in relevance to enactive and iconic modes

Note: $n=6$
Focus formulation

Post-focus

During and after focus formulation the situational relevance of the iconic mode may expand to other relevance types, such as studying the traditions of performance transmitted in the articulation marks

During and after focus formulation, the situational relevance of the 1st enactive mode may expand to other relevance types, such as studying the gestural language of other performers

During and after focus formulation, the situational relevance of the $2^{\text {st }}$ enactive mode may expand to other relevance types, such as conducting different analysis based on recordings

During and after focus formulation, the situational relevance of certain symbolic modes may increase, such as technological models (1st symbolic) and other symbolic information

Important information modes

Ideological models of music as the second mode of symbolic representations

Other symbolic information

Changes in situational relevance

Table IV.

Important information modes and changes in situational relevance among students focusing on music education

\section{Pre-focus}

Post-focus

The symbolic modes most relevant The participants focused their works to matters related to ideological when examining a general topic models and relevance of the other symbolic modes diminished During pre-focus, the enactive modes If own approach to instrument and musicianship was considered were often seen as not relevant significant from the viewpoint of the thesis, the importance of the enactive modes could slightly increase after and during focus formulation

Note: $n=5$

students, the importance of the enactive and iconic modes remained constant during the ISPs. However, in the interviews, two of the participating music students stated that the importance of music listening as the second enactive mode diminished as the task progressed. The most important symbolic mode for this participant group was technological models of music. See Table $\mathrm{V}$ for the summary of findings regarding students of music theory and composition.

\section{Discussion}

The most significant factor affecting the situational relevance judgments of music information were the context, namely the nature of the participants' tasks. Music performance students focusing on music education focused on the symbolic information modes and saw the enactive and iconic modes as less important. DocMus students focusing on music performance as well as students of music theory and composition viewed the enactive and iconic modes as important, but for different reasons related to the requirements of their task at hand. Furthermore, especially among DocMus students, the situational 


\section{Important information modes}

Receiving music as the second mode of enactive representations

Music making as the first mode of enactive representations

Technological models of music as the first mode of symbolic representations

Iconic representations of music

Changes in situational relevance

Pre-focus Focus formulation Post-focus

Study of the topic and analyzed pieces at The relevance of audio recordings may diminish after the more general level through listening of analyses become more detailed

audio recordings (2nd enactive)

Once the music analyses get more detailed, own playing $\left(1^{\text {st }}\right.$ enactive) becomes more relevant from the viewpoint of analyzes. Own playing is used to bring forth details of the pieces to be used in the analyses

Note: $n=3$

1245

Table V.

Important information modes and changes in situational relevance among students of music theory and composition

relevance type of the information modes could change significantly after and during the task-stage of focus formulation. This further supports the finding of prior research that it is useful to approach the concept of relevance as a context-sensitive and process-oriented user construct (Bateman, 1998; Vakkari and Hakala, 2000).

Previous research on the changing relevance judgments of textual documents has shown that once information seeker's task progresses, the notion of relevance also becomes more focused. This is due to that the information seeker has more readiness to identify pertinent texts in the later stages of the task, even if with text documents these changes could be subtle (Vakkari and Hakala, 2000, p. 559). The findings of the present paper regarding students focusing on music education suggest a similar dynamic with regard to task progress and relevance of textual documents; during and after the focus formulation, this participant group was able to narrow its focus to the symbolic or textual mode which was viewed as most relevant and in general the changes in the situational relevance of the important information modes were subtle. Within the tasks of DocMus students, the enactive and iconic modes were of most importance during the pre-focus stage topic exploration. During and after focus formulation, the increased ability to discern pertinent information led to the perceiving of the symbolic information modes as important and relevant due to new diverse reasons. This seems to suggest that tasks focusing on enactive outputs such as music performances are more expansive what comes to using the different modes of music information at different stages of tasks. This appears as somewhat contradictory to the music education students working to create a written thesis because they strived to narrow their focus into the most relevant symbolic information mode.

Some of the students of music performance focusing on music education found the enactive modes relevant to the extent that their situational relevance type underwent changes during the period of examination. Thus, the enactive modes may not only be relevant for music students writing written theses, but they also might incorporate several situational relevance types during a task aimed at a written thesis. The situational relevance types of the modes of music information among students of music education and music theory, as well as students of music composition will be examined in detail in forthcoming publications (for DocMus students, see Rousi et al., 2018).

The present paper utilized Kuhlthau's (2004) process survey instrument in order to identify the progress of the task performance. The modified process survey instrument also helped to identify participants whose tasks did not progress during the circa 130 days period of examination. As only half of the participants made significant progress in their task, the period of examination between the phases of data collection could have been longer. This was especially evident with DocMus students' extensive tasks of dissertations 
$\mathrm{JD}$

75,6

1246

on music. However, with this period of examination, the participants seemed to be able to recall their thoughts when answering the questionnaire in the first data collection phase which helped in identifying changes in the situational relevance of the information modes. Another alternative approach in methodology could have been not to lengthen the time period between data collection phases but to insert a third data collection phase after circa four months from the second one. This would have increased the share of music students making significant progress in their tasks while participating in this longitudinal study and thus likely would have provided more evidence regarding changes in situational relevance of the information modes. However, the methodology currently employed was nevertheless seen to produce results of interest in a topic where previous studies are scarce.

\section{Theoretical and practical implications}

The present paper was the first step towards examining how the situational relevance of music information of varying kinds is viewed during the different stages of informationseeking task performance. The findings demonstrate that not only the modes of music information were seen as situationally relevant for different reasons by the three music student groups when they started their tasks. Moreover, the perceived situational relevance of the information modes underwent changes as their tasks progressed to focus formulation and post-focus stages. The findings also showcase that approaching music information through frameworks that classify information sources at diverse levels of abstraction enables an accurate description of information-seeking processes and illuminates context-sensitive development of situational relevance of diverse music information of diverse modes.

With regard to implications on MIR design, it is noteworthy how much the nature of the tasks, i.e. focus on music performance, writing academic texts on music education or conducting music analyses affected the ways in which the participants viewed the situational relevance of the music information modes while performing information-seeking tasks. Conducting similar context-sensitive longitudinal studies examining the relevance of music information could deepen our understanding on how the situational relevance of music information varies in different types of tasks. This could, in turn, influence the MIR system design to better acknowledge the nature and the stage of a music-related task when recommending relevant materials.

\section{Limitations}

Due to the small number of the study participants, the findings describing informationseeking processes of students of music performance, music education and music theory and composition are not generalizable to all students representing these fields. For the same reason, it is possible that individual factors such as the student's information-seeking styles and habits have affected the empirical findings. Therefore, further research is needed to verify the results concerning the differences in information-seeking processes of the participating music student groups.

\section{Further research}

The situational relevance types of music information modes for students of music education and music theory and composition should be examined in more depth. More research is also needed to verify the present paper's findings regarding the differences in relevance dynamics of tasks aimed at music performances and of those aimed at written theses. Furthermore, similar research should be conducted to information-seeking tasks related to other artistic disciplines, such as other performing arts or visual arts. The previous approaches could prove to be useful in understanding how the situational relevance of various information modes change during information-seeking processes. 


\section{Conclusion}

This paper presents an account of how situational relevance of diverse music information modes changes in the ISPs of music students representing the fields music performance, music education and music theory and composition. The findings demonstrate that not only the modes of music information were seen as situationally relevant for different reasons by the three participating music student groups at the initial stage of task performance, but also that the situational relevance of the information modes was perceived differently between the music student groups as their tasks progressed to focus formulation and post-focus stages. The findings highlight the potential of context-sensitive approaches to music information seeking and the importance of conducting longitudinal studies elaborating how situational relevance may undergo changes during information-seeking processes.

\section{References}

Barry, C. (1998), "Document representations and clues to document relevance", Journal of the American Society for Information Science, Vol. 49 No. 14, pp. 1293-1303.

Bateman, J. (1998), "Changes in relevance criteria: a longitudinal study", in Preston, C. (Ed), Proceedings of the 61st American Society for Information Science Annual Meeting, Vol. 35, Information Today, Medford, NJ, pp. 23-32.

Bengtsson, I. (1977), Musikvetenskap: en översikt [Music Science: An Overview], Esselte Studium, Stockholm.

Brown, C. (2002), "Straddling the humanities and social sciences: the research process of music scholars", Library \& Information Science Research, Vol. 24 No. 1, pp. 73-94.

Bruner, J. (1966), Toward a Theory of Instruction, Harvard University Press, Cambridge.

Casey, M., Veltkamp, R., Goto, M., Leman, M., Rhodes, C. and Slaney, M. (2008), "Content-based music information retrieval: current directions and future challenges", Proceedings of the IEEE, Vol. 96 No. 4, pp. 668-696.

Cheng, J.Z. and Shen, J. (2014), "Just-for-me: an adaptive personalization system for location-aware social music recommendation", Proceedings of International Conference on Multimedia Retrieval, ICMR2014, pp. 1-8.

Dougan, K. (2015), "Finding the right notes: an observational study of score and recording seeking behaviors of music students", The Journal of Academic Librarianship, Vol. 41 No. 1, pp. 61-67.

Downie, S. (2003), "Music information retrieval”, Annual Review of Information Science and Technology, Vol. 37, pp. 295-340.

Downie, S. (2004), "The scientific evaluation of music information retrieval systems: foundations and future", Computer Music Journal, Vol. 28 No. 2, pp. 12-23.

Godøy, R. and Jensenius, A. (2009), "Body movement in music information retrieval”, Proceedings of the $10^{\text {th }}$ International Music Information Retrieval Conference, ISMIR2009, pp. 45-50.

Hunter, B. (2006), "A new breed of musicians: the information-seeking needs and behaviors of composers of electroacoustic music", Music Reference Services Quarterly, Vol. 10 No. 1, pp. 1-15.

Kim, S.-M. (2015), "Towards organizing and retrieving classical music based on functional requirements for bibliographic records (FRBR)", dissertation, University of Pittsburgh, Pittsburgh, PA, available at: https://pdfs.semanticscholar.org/ba2e/56b9b6d0300199d0f690 7e50619dc94d1f2a.pdf (accessed July 10, 2019).

Kim, T.E., Schmidt, E.M., Migneco, R., Morton, B.G., Richardson, P., Scott, J., Speck, J.A. and Turnbull, D. (2010), "Music emotion recognition: a state of the art review", Proceedings of the $11^{\text {th }}$ International Society for Music Information Retrieval Conference, ISMIR2010, pp. 255-266.

Kostagiolas, P.A., Lavranos, C., Korfiatis, N., Papadatos, J. and Papavlasopoulos, S. (2015), "Music, musicians and information seeking behaviour", Journal of Documentation, Vol. 71 No. 1, pp. 3-24. 
JD

75,6

1248

Kuhlthau, C. (2004), Seeking Meaning: A Process Approach to Library and Information Services, 2nd ed., Libraries Unlimited, Westport, NY.

Kuhn, T.S. (1996), The Structure of Scientific Revolutions, 3rd ed., University of Chicago Press, Chicago, IL.

Lai, K. and Chan, K. (2010), 'Do you know your music users' needs? A library user survey that helps enhance a user-centered music collection", The Journal of Academic Librarianship, Vol. 36 No. 1, pp. 63-69.

Lavranos, C., Kostagiolas, P. and Martzoukou, K. (2016), "Theoretical and applied issues on the impact of information on musical creativity: an information seeking behavior perspective", in Kostagiolas, P., Martzoukou, K. and Lavranos, C. (Eds), Trends in Music Information Seeking, Behavior, and Retrieval for Creativity, IGI Global, Hershey, PA, pp. 1-16.

Lavranos, C., Kostagiolas, P., Korfiatis, N. and Papadatos, J. (2016), "Information seeking for musical creativity: a systematic literature review",Journal of the Association for Information Science and Technology, Vol. 67 No. 9, pp. 2105-2117.

Lavranos, C., Kostagiolas, P.A., Martzoukou, K. and Papadatos, J. (2015), "Music information seeking behaviour as motivator for musical creativity: conceptual analysis and literature review", Journal of Documentation, Vol. 71 No. 5, pp. 1070-1093.

Liew, C. and Siong, S. (2006), "Beyond the notes: a qualitative study of the information-seeking behavior of ethnomusicologists", The Journal of Academic Librarianship, Vol. 32 No. 1, pp. 60-68.

Matson, J. and Shelley, A. (2013), "In search of music: a study of music consumption and search behaviors in undergraduate students", Music Reference Services Quarterly, Vol. 16 No. 4, pp. 218-231.

Pohjannoro, U. and Rousi, A.M. (2018), "The modes of music information in a compositional process. A case study", Journal of Documentation., Vol. 74 No. 5, pp. 987-1007.

Rousi, A.M., Savolainen, R. and Vakkari, P. (2016), "A typology of music information for studies on information seeking”, Journal of Documentation, Vol. 72 No. 2, pp. 265-276.

Rousi, A.M., Savolainen, R., Harviainen, M. and Vakkari, P. (2018), "Situational relevance of music information modes: an empirical investigation among Doctor of Music students", Journal of Documentation, Vol. 74 No. 5, pp. 1008-1024.

Saracevic, T. (2007), "Relevance: a review of the literature and a framework for thinking on the notion in information science. Part II: nature and manifestations of relevance", Journal of the American Society for Information Science, Vol. 58 No. 13, pp. 1915-1933.

Schamber, L. (1994), "Relevance and information behaviour", Annual Review of Information Science and Technology, Vol. 29, pp. 3-48.

Silverman, D. (2005), Doing Qualitative Research, 2nd ed., Sage Publications, London.

Su, J.-H., Yeh, H.-H., Yu, P.S. and Tseng, V.S. (2010), "Music recommendation using content and context information mining", IEEE Intelligent Systems, Vol. 25 No. 1, pp. 16-26.

Tarasti, E. (1994), A Theory of Musical Semiotics, Indiana University Press, Bloomington, IN.

Tesch, R. (1990), Qualitative Research: Analysis Types and Software, Falmer Press, London.

Trehub, S.E., Becker, J. and Morley, I. (2015), "Cross-cultural perspectives on music and musicality", Philosophical Transactions of the Royal Society B, Vol. 370 No. 1664, pp. 1-9.

Vakkari, P. (2001), "A theory of the task-based information retrieval process: a summary and a generalisation of a longitudinal study", Journal of Documentation, Vol. 57 No. 1, pp. 44-60.

Vakkari, P. and Hakala, N. (2000), "Changes in relevance criteria and problem stages in task performance", Journal of Documentation, Vol. 56 No. 5, pp. 540-562.

Wang, X., Rosenblum, D. and Wang, Y. (2012), "Context-aware mobile music recommendation for daily activities", Proceedings of the $20^{\text {th }}$ ACM International Conference on Multimedia, MM2012, pp. 99-108. 


\section{Appendix 1. Questionnaire used in the present study}

\section{Background information}

Alias:

(Use the same alias in both questionnaires. Your alias will not be published)

Study program:

Age:

How many years you have studied at the Sibelius Academy:

What is the main topic of your thesis? Choose one of the following

$\square$ music history

$\square$ ethnomusicology

\section{$\square$ music education}

$\square$ own artistic activity (e.g., composition or music performance) music theory

$\square$ Other topic, please define

\section{Phase of the information-seeking task}

2.1 What is your primary task concerning your thesis at the moment? Choose one of the following.

$\square$ Start of the thesis and identifying its general topic

$\square$ Examining information concerning a general topic and formulating a specific focus

Gathering information pertinent to a focused topic or finalizing the thesis

$\square$ Other, please define?

2.2 What are you thinking in the current phase of your task? Choose all options that apply.

$\square$ Organizing ideas and information

$\square$ Identifying possible alternative topics

- Becoming informed about the general topic

$\square$ Exhausting all possible sources of information

- Considering alternative topics in light of the requirements of the project

- Choosing the broad topic that has potential for success

- Comprehending the task before me

- Recognizing ways to draw the project to a close

- Considering alternative topics in the light of the information available to me

- Confronting the inconsistency and incompatibility in the information encountered

$\square$ Getting more interested and involved in ideas

$\square$ Defining and extending my specific topic

$\square$ Gaining a sense of direction and clarity

- Recalling a previous project when I searched for information

$\square$ Predicting success of each possible concentration

$\square$ Identifying several possible areas of concentration in the broad topic

Considering alternative topics in light of the things that are of personal interest to me

$\square$ Seeking information about my specific area of concentration

$\square$ Other, please define?

2.3 What are you doing in the current phase of your task (these musical aspects of your thesis are examined in more detail in the following section of the questionnaire)? Choose all that apply.

$\square$ I am getting acquainted with a music piece related to my topic by trying out different parts with my instrument

$\square$ I am rehearsing a piece for public performance

I am performing music in public

I I am doing preliminary music analyses related to my topic

I I am doing detailed music analyses related to my topic

$\square$ I am composing music

I am listening to music that is broadly related to my topic

$\square$ I am listening to a selected set of musical pieces 
JD

$\square$ Discussing the topic

Making a summary search of the library

$\square$ Skimming and scanning sources of information

$\square$ Outlining to organize information

$\square$ Reading over notes for themes

Making a preliminary search from the library

$\square$ Conferring with people who know the topic

$\square$ Writing about themes and ideas

$\square$ Reading about the topic

$\square$ Taking detailed notes on facts and ideas

$\square$ Taking brief notes on facts and ideas

$\square$ Rechecking sources for information initially overlooked

$\square$ Recording bibliographic citations

$\square$ Other, please define?

2.4 From the following, choose all adjectives that describe your emotions at the current phase of your task?

- Sure
- Disappointed
- Frustrated
- Relieved
- Confident
- Other, please define?

Confused

- Doubtful

Optimistic

Satisfied

Uncertain

Other, please define?

\section{Acquired or used sources of information}

\subsection{Playing or performing pieces yourself and information within this activity}

3.1.1 How important it is for you to play or perform pieces in the current phase of your theses task? Choose one of the following.

$\square$ Not important $\square$ Not that important $\square$ Important $\square$ Very important

3.1.2 Explain your previous answer

3.1.3 What information sources incorporating this information mode have you acquired or utilized during your thesis task? Choose all options that apply. Mark all applying information sources.

$\square$ Own personal rehearsing

$\square$ Making music with the academic faculty or in other rehearsals arranged at your university

$\square$ Making music in concerts arranged by the university

$\square$ Making music in rehearsals arranged outside the university (networks outside your academic institution)

$\square$ Making music in concerts or other public performances arranged outside the university (networks outside your academic institution)

$\square$ Different online and media services (e.g., Youtube, Sibelius Academy's "Do you know enough about rehearsing" [Tiedätkö harjoittelusta riittävästi] online material)

$\square$ Different materials available from the Sibelius Academy Library regarding music performance (e.g. instructional material regarding specific instruments)

(music notations from their own information mode, which is examined in section 3.3)

$\square$ Other information sources related to playing or performing pieces yourself, please define (music notations from their own information mode, which is examined in section 3.3)? 


\subsection{Music performances and information received from them (excluding playing or performing pieces yourself)}

3.2.1 How important is information received from different music performances (excluding playing or performing music yourself) in the current phase of your task? Choose one of the following.

$\square$ Not important $\square$ Not that important $\square$ Important $\square$ Very important

3.2.2 Explain your previous answer

3.2.3 What information sources incorporating this information mode have you acquired or utilized during your thesis task? Choose all options that apply. Mark all applying information sources.

Audio recordings available from the Sibelius Academy Library (SACD/CDs, vinyls)

$\square$ Sibelius Academy Library's electronic databases, licenced or produced by the Library, and audio recordings available through them (e.g., Classical Music Library, Contemporary World Music, Naxos Music Library, Doria)

Audio recordings or suggestions received from the personnel of Sibelius Academy Library

$\square$ Following concerts and rehearsals arranged by Sibelius Academy

Audio recordings or suggestions received from the teaching and academic faculty of Sibelius Academy

$\square$ Audio recordings or suggestions received from other students of Sibelius Academy

$\square$ Following concerts and rehearsals arranged outside of your academic institution

$\square$ Audio recordings or suggestions received from your networks outside your academic institution

$\square$ Own personal collection of audio recordings

$\square$ Retail stores and their online stores that sell audio recordings (e.g. Ostinato)

$\square$ Chargeable online music streaming services providing digital audio (e.g. Spotify)

$\square$ Other online and media services providing audio (e.g. YouTube, other social media, radio, online radio)

$\square$ Audio recordings available from the collections of other libraries

$\square$ Other information sources related music performances and information received from them (excluding playing or performing pieces yourself), please define?

\subsection{Music scores or other music notation types and information received from them}

3.3.1 How important are music scores or other notation types in the current phase of your theses task? Choose one of the following.

$\square$ Not important $\square$ Not that important $\square$ Important $\square$ Very important

3.3.2 Explain your previous answer

3.3.3 What information sources incorporating this information mode have you acquired or utilized during your thesis task? Choose all options that apply. Mark all applying information sources.

Music scores and notations available from the Sibelius Academy Library 
JD $\square$ Sibelius Academy Library's collection of anthologies, collected works of composers, score manuscripts or historically valuable scores

$\square$ Sibelius Academy Library's electronic databases, licenced or produced by the Library, and digital music scores available through them (Classical Scores Library, Doria)

Music scores or suggestions received from the personnel of Sibelius Academy Library

$\square$ Music scores, extracts from course materials or suggestions received from the teaching and academic facultyof Sibelius Academy

$\square$ Music scores or suggestions received from other students of Sibelius Academy

$\square$ Music scores or suggestions received from your networks outside your academic institution

$\square$ Own personal collection of music scores

$\square$ Retail stores and their online stores that sell music notations (e.g. Ostinato)

$\square$ Free online services focusing on digital music scores (e.g. American Memory, Bach Cantatas Website, IMSLP/Petrucci Music Library, Musopen.org) and materials available through them

$\square$ Chargeable online services focusing on digital music scores (e.g. Boosey \& Hawkes - Sheet music download, Luck's Music Library, Sheetmusicdb.net) and materials available through them

$\square$ Music scores available from the collections of other libraries

$\square$ Other information sources related music scores and other music notation types and information received from them (excluding playing or performing pieces yourself), please define?

\subsection{Information examining music theory (e.g. harmony, voice leading, music analysis and orchestration)}

3.4.1 How important is information examining music theory in the current phase of your theses task? Choose one of the following.
$\square$ Not important
$\square$ Not that important
$\square$ Important
$\square$ Very important

3.4.3 What information sources incorporating this information mode have you acquired or utilized during your thesis task? Choose all options that apply. Mark all applying information sources.

$\square$ Sibelius Academy Library's collection of printed books, printed journals and other printed materials

$\square$ Sibelius Academy Library's collection of printed theses

$\square$ Sibelius Academy Library's collection of electronic materials and databases (e.g. RIPM, IIMP), including materials such as electronic journals or theses or electronic encyclopedias

$\square$ Sibelius Academy Library's eThesis database and its electronic theses

$\square$ Materials or suggestions received from the personnel of Sibelius Academy Library

$\square$ Materials or suggestions received from the teaching and academic faculty of Sibelius Academy

$\square$ Materials or suggestions received from other students of Sibelius Academy 
Materials or suggestions received from your networks outside your academic institution

Music

$\square$ Own personal collection of literature

$\square$ Retail stores and their online stores that sell this literature (e.g. Ostinato)

$\square$ Free online services focusing on music (e.g.. Aleatori. other open courseware - e.g. MIT, Bach bibliography, Beethoven gateway DOAJ - Journal of Music History Pedagogy, DOAJ - Journal of Seventeenth-Century Music)

$\square$ Other online and media services (incl. Delicious.com, discussion forums, email lists)

$\square$ Printed or electronic collections of other libraries or archives

$\square$ Other information sources examining music theory, please define?

\subsection{Information examining music but not directly the qualities manifest in it (such as music history, philosophy of music, aesthetics of music)}

3.5.1 How important is Information examining music but not directly the qualities manifest in it (such as music history, philosophy of music, aesthetics of music) in the current phase of your theses task? Choose one of the following.
$\square$ Not important
$\square$ Not that important
$\square$ Important
$\square$ Very important

3.5.2 Explain your previous answer

3.5.3 What information sources incorporating this information mode have you acquired or utilized during your thesis task? Choose all options that apply. Mark all applying information sources.

$\square$ Sibelius Academy Library's collection of printed books, printed journals and other printed materials

$\square$ Sibelius Academy Library's collection of printed theses

$\square$ Sibelius Academy Library's collection of electronic materials and databases (e.g. RIPM, IIMP), including materials such as electronic journals or theses or electronic encyclopedias

$\square$ Sibelius Academy Library's eThesis database and its electronic theses

$\square$ Materials or suggestions received from the personnel of Sibelius Academy Library

Materials or suggestions received from the teaching and academic faculty of Sibelius Academy

$\square$ Materials or suggestions received from other students of Sibelius Academy

$\square$ Materials or suggestions received from your networks outside your academic institution

$\square$ Own personal collection of literature

$\square$ Retail stores and their online stores that sell this literature (e.g. Ostinato)

$\square$ Free online services focusing on music (e.g.. open courseware - MIT, Bach bibliography, Beethoven gateway DOAJ Journal of Music History Pedagogy, DOAJ - Journal of Seventeenth-Century Music)

$\square$ Other online and media services (incl. Delicious.com, discussion forums, email lists)

$\square$ Printed or electronic collections of other libraries or archives

$\square$ Other information sources examining this information, please define? 
JD

\subsection{Information not examining music (e.g. scientific writing, educational sciences, sociology, philosophy or fiction)}

3.6.1 How important is information not examining music in the current phase of your thesis task (e.g. scientific writing, educational sciences, sociology, philosophy or fiction)? Choose one of the following.
$\square$ Not important
$\square$ Not that important
$\square$ Important
$\square$ Very important

3.6.2 Explain your previous answer

3.6.3 What information sources incorporating this information mode have you acquired or utilized during your thesis task? Choose all options that apply. Mark all applying information sources.

$\square$ Sibelius Academy Library's collection of printed books, printed journals and other printed materials (literature related to grammar, educational sciences or philosophy, for example)

$\square$ Sibelius Academy Library's collection of electronic materials and databases, including materials such as electronic journals or theses or electronic encyclopedias

$\square$ Materials or suggestions received from the personnel of Sibelius Academy Library

$\square$ Materials or suggestions received from the teaching and academic faculty of Sibelius Academy

$\square$ Materials or suggestions received from other students of Sibelius Academy

$\square$ Materials or suggestions received from your networks outside your academic institution

$\square$ Own personal collection of literature

$\square$ Retail stores and their online stores that sell this literature (e.g. Ostinato)

$\square$ Free online services focusing on music (e.g. Sibelius Academy's language center's materials, other open courseware)

$\square$ Other online and media services (incl. Delicious.com, discussion forums, email lists)

$\square$ Printed or electronic collections of other libraries or archives

$\square$ Other information sources not examining music, please define? 


\begin{tabular}{|c|c|c|c|c|}
\hline Items constitutive of the category of thoughts & $\begin{array}{c}\text { Phase I } \\
(\%)\end{array}$ & $\begin{array}{c}\text { Phase II } \\
(\%)\end{array}$ & $\begin{array}{c}\text { Change } \\
\%\end{array}$ & \\
\hline Recognizing ways to draw the project to a close & 29 & 57 & +28 & 1255 \\
\hline Seeking information about my specific area of concentration & 43 & 64 & +21 & \\
\hline Organizing ideas and information & 79 & 93 & +14 & \\
\hline Confronting the inconsistency and incompatibility in the information encountered & 21 & 29 & +8 & \\
\hline Defining and extending my specific topic & 21 & 29 & +8 & \\
\hline Exhausting all possible sources of information & 43 & 50 & +7 & \\
\hline Considering alternative topics in light of the requirements of the project & 21 & 21 & +0 & \\
\hline Gaining a sense of direction and clarity & 14 & 14 & +0 & \\
\hline Identifying possible alternative topics & 57 & 29 & -28 & \\
\hline Becoming informed about the general topic & 71 & 43 & -28 & \\
\hline Choosing the broad topic that has potential for success & 36 & 14 & -22 & \\
\hline Comprehending the task before me & 50 & 29 & -21 & Table AI \\
\hline Recalling a previous project when I searched for information & 29 & 14 & -15 & Changes in the \\
\hline Predicting success of each possible concentration & 57 & 43 & -14 & category of thoughts \\
\hline Considering alternative topics in light of the things that are of personal interest to me & 14 & 0 & -14 & among the \\
\hline Identifying several possible areas of concentration in the broad topic & 38 & 29 & -9 & participants $(n=14)$ \\
\hline Getting more interested and involved in ideas & 43 & 36 & -7 & between the data \\
\hline Considering alternative topics in the light of the information available to me & 21 & 14 & -7 & collection points \\
\hline
\end{tabular}

\section{Appendix 3}

\begin{tabular}{|c|c|c|c|c|}
\hline Items constitutive of the category of actions & $\begin{array}{c}\text { Phase I } \\
(\%)\end{array}$ & $\begin{array}{c}\text { Phase II } \\
(\%)\end{array}$ & $\begin{array}{c}\text { Change } \\
\%\end{array}$ & \\
\hline Reading about the topic & 71 & 86 & +15 & \\
\hline Writing about themes and ideas & 36 & 50 & +14 & \\
\hline I am getting acquainted with a music piece related to my topic by trying out & & & & \\
\hline different parts of it with my instrument & 29 & 43 & +14 & \\
\hline I am doing detailed music analyses related to my topic & 14 & 21 & +7 & \\
\hline I am rehearsing a piece for public performance & 7 & 14 & +7 & \\
\hline I am performing music in public & 0 & 7 & +7 & \\
\hline Skimming and scanning sources of information & 57 & 57 & +0 & \\
\hline I am listening to music that is broadly related to my topic & 50 & 50 & +0 & \\
\hline I am doing preliminary music analyses related to my topic & 36 & 36 & +0 & \\
\hline Taking detailed notes on facts and ideas & 29 & 29 & +0 & \\
\hline Rechecking sources for information initially overlooked & 14 & 14 & +0 & \\
\hline Making a summary search of the library & 7 & 7 & +0 & \\
\hline I am composing music & 0 & 0 & +0 & \\
\hline Making a preliminary search from the library & 64 & 21 & -43 & \\
\hline Conferring with people who know the topic & 50 & 11 & -39 & Table AII. \\
\hline Reading over notes for themes & 43 & 7 & -36 & Changes in the \\
\hline Discussing the topic & 86 & 71 & -15 & category of actions \\
\hline Taking brief notes on facts and ideas & 36 & 21 & -15 & among the \\
\hline I am listening to a selected set of musical pieces & 50 & 36 & -14 & participants $(n=14)$ \\
\hline Outlining to organize information & 50 & 43 & -7 & between the data \\
\hline Recording bibliographic citations & 36 & 29 & -7 & collection points \\
\hline
\end{tabular}


75,6

Table AIII.

Changes in the category of emotions among the participants $(n=14)$ between the data collection points
Appendix 4

\begin{tabular}{lccc}
\hline Items constitutive of the category of emotions & Phase I $(\%)$ & Phase II (\%) & Change \% \\
\hline Relieved & 0 & 21 & +21 \\
Optimistic & 66 & 86 & +20 \\
Sure & 0 & 14 & +14 \\
Disappointed & 0 & 0 & +0 \\
Confused & 50 & 0 & -50 \\
Doubtful & 36 & 14 & -22 \\
Uncertain & 43 & 29 & -14 \\
Confident & 64 & 57 & -7 \\
Frustrated & 21 & 14 & -7 \\
Satisfied & 21 & 14 & -7 \\
\hline
\end{tabular}

$+20$

$+0$

$-50$

$-14$

$-7$

-7
-7 
Appendix 5

Docmus students focusing on music

\section{Music information} performance $(n=6)$

Iconic representations of music

Music making as the first mode of enactive representations

Receiving music as the second mode of enactive representations

Ideological models of music as the second Important (2.3)

mode of symbolic representations

Other symbolic information

Important (1.6)

Phase I (avg.)

Very important (2.6)

Important (2.2)

Important (2)

Technological models of music as the first Not that important (1.3) mode of symbolic representations
Music performance students focusing on $\quad$ Phase I (avg.) $\quad$ Phase II (avg.) $\quad$ Change in avg. music education (incl. Docmus Student G)

$(n=5)$

Ideological models of music as the second Very important (2.6)

mode of symbolic representations

Other symbolic information

Important (2.4)

Very important (2.8)

Very important (2.6)

Important (2.5)

Important (2.5)

Important (2.3)

Important (2.2)

Receiving music as the second mode of enactive representations

Music making as the first mode of enactive representations

Technological models of music as the first Not important (0.4)

mode of symbolic representations

Iconic representations of music

Not important (0.2)

Not important (0)

Phase II (avg.)

Students of music theory and compos
focusing on music analysis $(n=3)$

Receiving music as the second mode of enactive representations

Music making as the first mode of enactive representations

Technological models of music as the first Important (2.3)

mode of symbolic representations

Iconic representations of music

Important (2)

Important (2)

Very important (2.6)

Important (2.3)

Important (2.3)

Important (2)

Ideological models of music as the second Not that important (1.3) Not that important (1.3) mode of symbolic representations

Other symbolic information

Not important (0.3)

Not important (0.3)
Change in avg.

$$
\begin{aligned}
& +0 \\
& +0.3 \\
& +0.5 \\
& +0 \\
& +0.6 \\
& +0.5
\end{aligned}
$$

$$
\begin{aligned}
& +0.2 \\
& +0 \\
& +0.8 \\
& +0.6 \\
& -0.4
\end{aligned}
$$

Change in avg.

+0.6
-0.3
+0
+0
+0
+0

Table AIV.

The average perceived importance of modes of music information categorized per music student group

\section{Corresponding author}

Antti Mikael Rousi can be contacted at: antti.m.rousi@aalto.fi

For instructions on how to order reprints of this article, please visit our website: 